\title{
A STEM Model to Engage Students in Sustainable Science Education through Sports: A Case Study in Qatar
}

\author{
Ruba Ali, Jolly Bhadra, Nitha Siby, Zubair Ahmad (D) and Noora Jabor Al-Thani * \\ Young Scientists Center (YSC), Qatar University, Doha 2713, Qatar; ruba.ali@qu.edu.qa (R.A.); \\ jollybhadra@qu.edu.qa (J.B.); nitha.siby@qu.edu.qa (N.S.); zubairtarar@qu.edu.qa (Z.A.) \\ * Correspondence: n.al-thani@qu.edu.qa; Tel.: +974-4403-3979
}

Citation: Ali, R.; Bhadra, J.; Siby, N.; Ahmad, Z.; Al-Thani, N.J. A STEM Model to Engage Students in Sustainable Science Education through Sports: A Case Study in Qatar. Sustainability 2021, 13, 3483. https://doi.org/10.3390/su13063483

Academic Editor: Larry J. Grabau

Received: 4 March 2021

Accepted: 18 March 2021

Published: 21 March 2021

Publisher's Note: MDPI stays neutral with regard to jurisdictional claims in published maps and institutional affiliations.

Copyright: (c) 2021 by the authors. Licensee MDPI, Basel, Switzerland. This article is an open access article distributed under the terms and conditions of the Creative Commons Attribution (CC BY) license (https:// creativecommons.org/licenses/by/ $4.0 /)$.

\begin{abstract}
Sports has the potential to integrate with different scientific subjects, including materials science and engineering, making it an ideal approach to enhance the students' affinity toward sustainable education in science, technology, engineering, and mathematics (STEM). Amid gradual educational reformations in the state of Qatar, a distinctive STEM program titled, "Science in Sports" (SIS) was launched to investigate STEM integrated learning in secondary school students. The participant students, 248 students (112 females and 136 males) from 15 different government-operated (public) secondary schools, from rural and urban areas, were given STEM workshops on one of the sports materials, during this pilot study, resultantly challenging them to engineer a sports product. The study employed a mixed-method study in which quantitative approaches were applied to analyze the program effectiveness, with a $t$-test statistical analysis performed over data collected from a period of five continuous years from 2012 to 2017 in five different cycles. A more dominant data collection included pre and post surveys, substantiating observations of the program facilitator and their schoolteachers were included in this research and development (R\&D) study to review the student learning behavior for a qualitative approach. Moreover, the results of the strength, weakness, opportunities, and threats (SWOT) analysis provided an overview of the program's effectiveness in implicating the engagement of the students in exhibiting their prototypical skills in engineering sports products along with STEM literacy. Apart from understanding the scientific concepts/principles applied in simple sports applications, student attitudes toward STEM fields augmented, as witnessed by the student productivity.
\end{abstract}

Keywords: sustainable science education; science implementation; youth empowerment; high school students; STEM; sports science

\section{Introduction}

Sports can promote social integration, economic development, develop teamwork capabilities, and improve physical and mental health. The state of Qatar has been recently brought to the limelight of the sports industry because it has grabbed the opportunity to host the most sought-after sports event-the FIFA world cup 2022. The coverage and discussions on the event and the wide-spread enthusiasm for the sports is a well-timed opportunity for the educational community to emphasize the positive impact of sports on students of all ages. In this context, trends show a growing inclination in youth toward sports and its related disciplines [1]. A significant percentage of high school students actively participate in sports and enjoy the competitive spirit, recreation, or personal development. Educators believe sports as paramount while providing a wholesome educational experience [2]. They are inspired by successful programs that use sports to empower the youth and educate them. There are studies on successful programs launched in Latin America and the Caribbean that achieved profound results. Additionally, several case studies have been performed on working with youth who were hooked to formal education through sports, changing their lives for the better and paving the way to better 
employment opportunities [2]. Their study describes the success of programs such as "A Ganar," which implemented team-based sports to help at-risk youth learn self-employment skills and enhance their physical, cognitive, and intellectual growth. In light of these studies, a rich background literature was collated by the research team on similar programs to understand the outcomes of implementing sports or sports-based techniques in learning. They were trying to overcome the shortcomings in students' learning goals in Qatar.

Our research program aims to couple science, technology, engineering, and mathematics (STEM) learning with sports in an advanced and different way than the previous reports, taking into account various influential factors in generating considerable interest in science education. We developed different concepts to create an innovative and thoughtful sports-based program capable of enhancing students' attitudes to STEM curriculum and STEM-driven careers. The program requirements needed to consider the factors of an out-of-school environment and supported the construction of a workshop for high school students, providing STEM activities. Apart from improving STEM literacy, this research was also capable of observing multiple competencies in students that could alleviate their cognitive behavior.

\subsection{Relevant Literature Background}

An uphill challenge faced by educators in Qatar in the recent past was the lack of sufficient development of STEM skills in students. Despite massive effort and investment made toward enriching the STEM program by authorities in the past two decades, the field is still unable to completely meet the great demand of a highly educated workforce that can support a knowledge-based economy. Countries that focused on STEM early on have embarked on a journey of innovations that has started steering the wheel of the global economy to their benefit $[3,4]$. Hence, the significance of STEM and increasing reliance on the STEM workforce cannot be downplayed for innovation-driven countries trying to maintain leadership in the world's economy [5-7]. Unfavorably for Qatar, various reports cite concerns regarding the lack of qualified Qatari STEM professionals and an obvious deficit in the level of learned skills itself [8-11]. This means strengthening the STEM discipline-its courses, content, or faculties-in itself is not enough; instead, educators should delve deeper into understanding the attitudes or underlying approach of Qatari youth toward STEM education. Identifying what quickly generates interest in sports and applying the same principles to education might be a pioneering but straightforward step in creating a positive impact in young minds to instill interest in STEM learning.

Many educational researchers provided direct insights into improving students' STEM interests with the help of activities instead of traditional instruction [12]. Citing numerous examples of integrating STEM, Wendell et al. [13] incorporated engineering design into the science curriculum with LEGO Mindstorm Kits. Subsequent results were profound, and it proved that students learn scientific concepts faster and better than an instruction-only curriculum. Having students participate in STEM activities is considered an assuring way to increase interest in STEM subjects and foster STEM literacy [6].

\section{Role of Self-Motivation and Motivational Factors}

Personal interest is another crucial factor in a student choosing to learn any discipline aiming to establish a career path [14]. Students across all socio-economic backgrounds find school education and learning disconnected from the real world, which makes schoolwork uninspiring or boring, gradually leading to underperformance in school. One of the key traits here that sets some students apart is self-motivation or personal interest. Evidence from previous studies suggests that students set their dispositions toward disciplines such as mathematics and science early in life much before higher education [12,15], indicating the crucial role of various motivation enhancing tools or techniques in modeling student interest at the right stage of growth. It was hypothesized by the Texas Academy of Mathematics and Science (TAMS) that students of different age groups might possess the competencies and skills required to become STEM professionals at varying degrees. 
It could be an area of importance and interest for educational researchers to identify the key influential factors such as individual interests, teachers, curriculum, and out-ofschool activities that can cultivate motivation in children of all ages. They believe that certain instigating factors can lead many students to favor STEM disciplines, target STEM careers, and promote broader participation in the future STEM workforce. Kilpatrick [16] recommended sports participation as an effective intrinsic motivator, which is also closely related to being a recommended youth development driver in Qatar and can inspire involvement without external incentives. Sports-based activities also act as drivers as in one of the dimensions of motivation, "Motivation to accomplish" [17]. It is also well supported by Choi and Song [18] study in which they discuss the effectiveness of sports in developing life skills and its potential to contribute to a wide range of subjects to make them palatable for students. Hence, we focused on an approach that could apply the students' interest in sports in encouraging them to participate in STEM activities that "speak" science through sports.

\subsection{Conceptual Framework}

Our method of projecting science through sports-driven activities was based on many analytical findings reported in different previous studies [19-21]. A detailed systematic study was performed on diverse research evidence determining factors for a student's STEM-driven "interest" in secondary education, focusing on both personal and social aspects (both parental and cultural). While introducing the concept of motivational factors, Hanrahan [20] implicated in her study that implementing more activities to reinforce positive attitudes for self-direction is preferential in active learning. Sports-driven activities creating situations similar to that in real-life problems were proven to enhance positive attitudes with their contribution to cognitive skills such as peer collaboration, problem solving, curiosity. These activities implemented to promote student-centered learning are a realistic approach $[19,21,22]$ because they stimulate curiosity through problem-based situations [21]. These activities also enhance logical reasoning, helping the children attain better emotional, social, and physical well-being [23].

Taking into account sports-driven activities, it was crucial for us to construct a wellcoursed framework of activities that can cultivate curiosity, STEM interest and consequently motivate participants to consider careers in similar fields, etc. The Material World Module (MWM) program, which aimed at instilling collaborative scientific research and engineering skills in high school students [24], provided adequate research backings to follow an inquiry and design methodology in our study. This Methodology introduces students to familiarize themselves through technological design, urging them to engage in hands-on activities to demonstrate how science is applied in our daily life routine. We developed the workshops, keeping the study evidence related to the importance of inquiry [25], problem solving, technical experience, and engineering projects to influence students' attitudes toward learning and enhance their science process skills. The first set of workshop activities was developed initially to aim to design sports products such as golf balls and baseballs. These two products were chosen randomly, inspired by the study conducted by [24]. Later, another set of workshop activities were constructed to consider designing sports products such as "concrete bowling ball" and "concrete boat" inspired from the competitions held by the American Concrete Institute (ACI) [26] and American Society of Civil Engineers (ASCE) National Concrete Canoe Competition (NCCC) [27]. However, both workshop activities (details in Figure 1 and Methodology Section, page 13) helped the students understand the structure and physical behavior of diverse composites such as concrete and other multi-layered sports materials and realize the science and correlating their application in daily life. In both sets of sports products (from workshops 1 and 2), we intended to develop the correlation between the underlying scientific concepts in each workshop offering the scientific principles in sports product development. The structure of implementing activities was similar in both the workshops, and the activities complement each other and lead the students to their respective design challenges. 

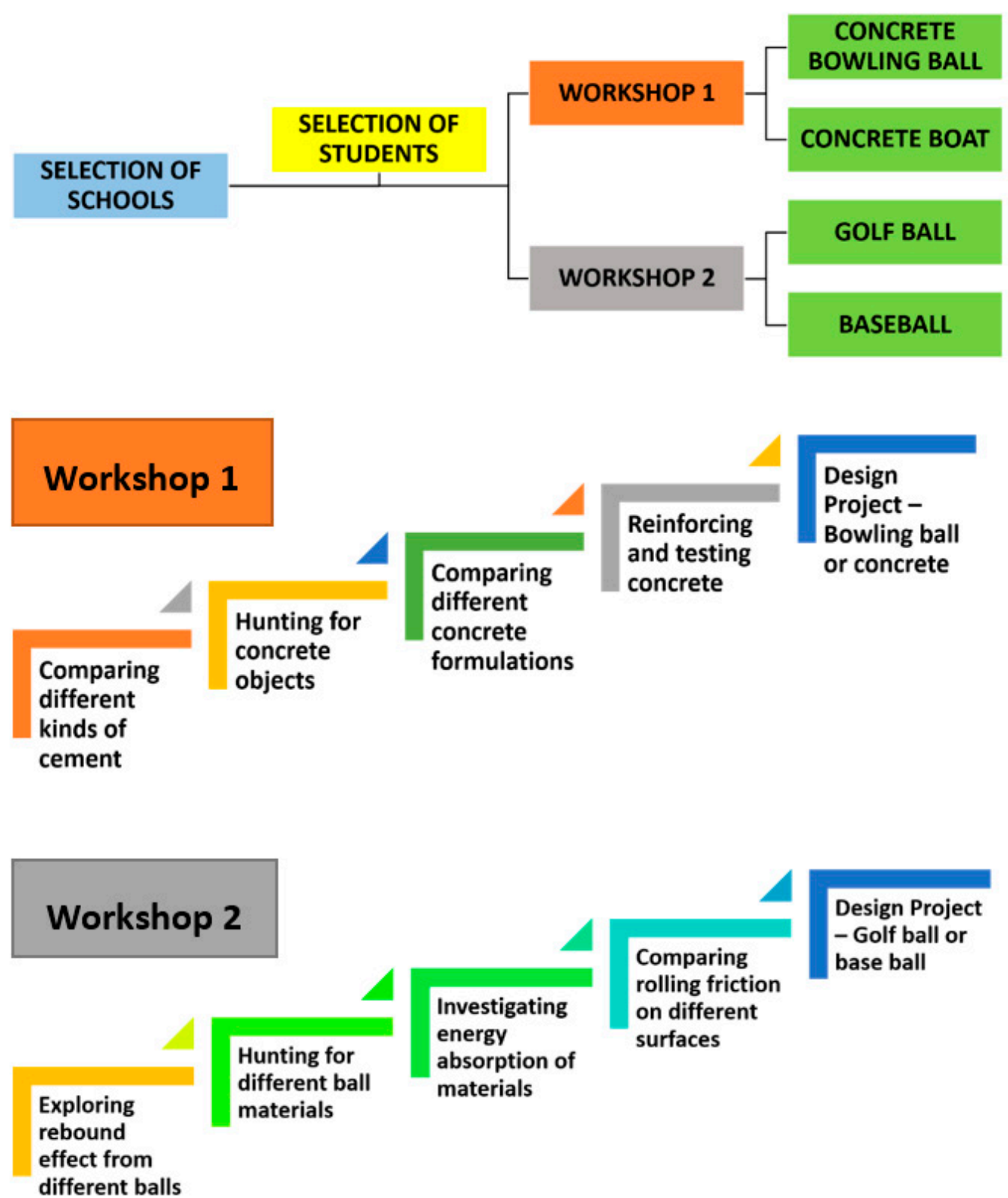

Figure 1. Schematic diagram of "Science in Sports" program methodology. The activity layout is provided for each workshop, demonstrating the daily activities for each day, Workshop 1 and Workshop 2 are directed to learn about concrete materials and sports materials, respectively. Regardless of the layout, the design project does not culminate on day 5 and takes nearly three months to complete after repetitive testing.

\subsection{Research Objectives}

The study was based on a program, "Science in Sports" (SIS), intended to steer high school students' passion in sports to explore the embedded science and gradually evolve into aspirants in STEM fields. The study emphasizes the program's successful integration of science in sports by solving engineering design challenges that arise while developing a sports product. The research objective was solely focused on acquainting them with STEM and its relevance in daily life by engineering simple sports products. The research questions that need to be addressed during our study are

1. Did the student understand the importance of STEM by experiencing science through sports product engineering?

2. Will the student consider a STEM-driven career resultantly in the future? 
3. Were the students able to understand and correlate scientific principles to the applications in daily life?

Apart from the above questions, the research was capable of deriving the exceptional secondary students' dispositions and self-efficacy in carrying out scientific experiments. The learning environment bolstered by sports products-driven challenges is an influencing factor that will be utilized in attracting Qatar's secondary youth to attain the program goals. Integrating sports as a carrier for acquainting scientific knowledge, the study will examine the diverse possibilities in promoting science process skills, reinforcing their attitudes toward science and engineering fields by intriguing them for creative learning.

\section{Materials and Methods}

The SIS program was designed and evaluated by employing a mixed-method study that implemented both quantitative and a more dominant qualitative analysis. While the former method used statistical tools to assess student attitudes toward STEM importance, relevance in daily life and future careers, the latter involved the observations of facilitators and school teachers who mentored the students during the program. Other qualitative data were retrieved from field notes, media (photos and videos), and student artifacts to derive an outlook on developing reasoning competencies and dispositions of the students as they progressed through the research. The annual program functioned within a three-month tentative period. The students experienced science and engineering through a science workshop directing them to construct a sports product for the engineering design challenge (Figure 1).

\subsection{Participants and the Educational Context}

The current study was conducted on 248 high school students including 112 girls and 136 boys from grades 10 and 11, who attended the SIS program from 2012 to 2017 in five cycles, over the five continuous years. The three-month time taken by each batch of students in one year for participating in the program was addressed as one cycle, and therefore, the study witnessed five batches of students from 15 schools over five cycles, as in Table 1. The participant students were provided with STEM workshops on different types of composite materials. While some schools were provided with "Workshop 1," for familiarizing themselves with concrete composites, other participating schools engaged in "Workshop 2" on some other sports material used for rebounding balls. The schools were assigned either of the topics on a random choice. For the first two cycles, the schools were from urban areas, whereas the schools involved in the experimental study during the third cycle were from rural areas, hence a smaller number of participants. However, in consequent years, we experimented on students from both urban (fourth cycle) and rural schools (fifth cycle), respectively.

Table 1. Demographic details of participants and Qatari student percentage. The total participant count for all five years is 275 . However, there were student withdrawals, and hence the study was conducted on a fewer number of participants (248) according to the questionnaire analysis, for those who have completed both pre and post questionnaires.

\begin{tabular}{|c|c|c|c|c|c|c|c|c|c|c|c|c|}
\hline \multirow[t]{2}{*}{ Cycle } & \multicolumn{4}{|c|}{ Total Number of Students } & \multicolumn{2}{|c|}{$\begin{array}{c}\text { Number of } \\
\text { Withdrawals (Nw) }\end{array}$} & \multicolumn{4}{|c|}{ Qatari Students } & \multicolumn{2}{|c|}{ Schools } \\
\hline & $\mathbf{M}$ & $\%$ & $\mathbf{F}$ & $\%$ & Nw & $\%$ & $\mathbf{M}$ & $\%$ & $\mathbf{F}$ & $\%$ & $\mathbf{M}$ & $\mathbf{F}$ \\
\hline Cycle 1: 2012 & 24 & 47.1 & 27 & 52.9 & 0 & 0 & 19 & 79.1 & 26 & 96.2 & 1 & 1 \\
\hline Cycle 2: 2013 & 36 & 60 & 24 & 40 & 4 & 6.6 & 36 & 100 & 24 & 100 & 2 & 1 \\
\hline Cycle 3: 2014 & 24 & 63.5 & 16 & 36.5 & 5 & 12.5 & 18 & 75 & 14 & 91.3 & 2 & 1 \\
\hline Cycle 4: 2015 & 36 & 60 & 24 & 40 & 8 & 13.3 & 31 & 86.1 & 21 & 87.5 & 2 & 1 \\
\hline Cycle 5: 2016 & 29 & 45.3 & 35 & 54.6 & 10 & 15.6 & 27 & 93.1 & 35 & 100 & 1 & 2 \\
\hline Total & 149 & 54.1 & 126 & 45.8 & 27 & 9 & 131 & 87.9 & 120 & 95.2 & 8 & 6 \\
\hline
\end{tabular}


The number of schools participating per cycle was then limited to three due to the restricted working time that could be engaged by the facilitator for the workshop hours and the product development phase that took place during their after-school period. The engineering of sports products consumed most of the program schedule because it was carried out within two months. Even though the program tenure was three months, a certain amount of time (as mentioned in the next section) was taken off for their regular school activities, including examinations scheduled according to the academic calendar.

The schools with maximum national student enrollment were chosen for the program during the initial screening process because the study primarily targeted Qatari students and their development. The schools were also requested to strictly maintain at least 75\% of national students for the program (due to the aim of the national capacity building). The final filtrate of students was selected according to the first-come, first-served basis, regardless of their intellectual capacity, and was grouped into students of three or four, maintaining a demographic ratio of non-national students and national students as 1:2 or 1:3, respectively, as in the case of participation of non-national students. (refer to Table 1).

The program was organized and delivered by the program facilitator, who is also the first author of this article. She holds a degree in engineering and has seven years of experience in STEM education. She is skilled in identifying the key areas of interest in a student and helps in applying them to overcome their learning deficits. She has experience designing and delivering around 90 engineering workshops for school students ranging from primary and secondary stages. The findings stated in this article corresponds to her observations noted in the daily report for each session and interaction with the students. For this study, with the assistance of other STEM professionals (PhD/Masters/bachelor's degree holders) of the Al-Bairaq team at the Qatar University Young Scientists Center (YSC), field notes, observations, and various resources were employed for the detailed analysis. Here, it is essential to mention that the YSC team has an extensive 10 years of experience in constructing workshops and educational activities. Table 1 details the number of participants and the percentage of Qatari student participation during each cycle.

\subsection{Methods}

The facilitator offered extensive two-hour daily workshops for a week with diverse hands-on activities (refer to Figure 1) to engage the students in experiential learning. The main goal of providing workshops to the students was to acquaint them with enough scientific information to design and construct the sports products-concrete boat, bowling ball, golf ball, and baseball. Each school was either provided with STEM workshops"Workshop 1" and "Workshop 2" (refer to Figure 1)-leading to the respective sports products. The workshops were followed by informal sessions for designing and constructing the product. During these sessions, the students had free choice to carry out the procedure; however, they would have to adhere to the facilitator's evaluation criteria, as in Table 2. These sessions were also allocated to repeated testing and designing of the product prototypes. In case of failure in creating the product according to the desired criteria, they would have to start over again or fix the products for positive results. The facilitators recorded student responses and learning behavior during the activities from attending workshops until they accomplished the final products. The facilitator observations were later analyzed to understand the student response or learning behavior exhibited during their project course.

The method exercised on the students through each of the following workshops is briefed below.

\subsubsection{Workshop 1}

Students' groups provided with "Workshop 1" were monitored by their respective schools for successful completion of a concrete boat or a concrete bowling ball as a final product. Workshop 1 taught students about concrete materials, the making of concrete, the different properties of concrete composites, and their diverse applications through a set 
of diverse activities developed by integrating all STEM subjects. The activities that were carried out to satisfy the workshop objectives are detailed hereafter (Figure 1):

- Activity 1: Comparing different kinds of cement-The workshop started with an ice-breaking experiment, wherein the students studied the different types of cement, one of the key ingredients in the concrete composite. They explored their hardening rates by measuring in different weights and analyzing the consequent results. They plotted graphs and interpreted them, thereby understanding the necessary science behind the process;

- Activity 2: Hunting for concrete objects-They researched different concrete applications, thereby increasing students' awareness of the most common infrastructure material. This activity was crucial in enhancing students' inquiry and research skills as they observe, question, learn, and deduce reasons behind using concrete materials;

- Activity 3: Comparing different concrete formulations-They familiarized themselves with the different ratios of ingredients/aggregates, i.e., sand, gravel, and cement, by experimenting with them to understand the properties of concrete, mainly density, hardness, and strength, according to the difference in ratios. They compared cement with concrete blocks and studied the packing of different aggregates to understand how each aggregate ratio affects concrete density;

- Activity 4: Reinforcing and testing concrete-The students grasped the effect of reinforcing materials on concrete properties, understanding their effect on strength and hardness. Moreover, they also tested the reinforced concrete blocks and compared them with non-reinforced concrete using strength-test apparatus, confirming the superior quality over the other.

Design project-All the above activities led the students to acquire the necessary knowledge in creating one of the sports products, i.e., a concrete bowling ball or a concrete floating boat, as a part of the design project. The workshop put forth design challenges for the students to choose the sports product for the design project and construct according to the preset criteria (refer to Table 2). The students interpreted the correct mixing-proportions for adequate sports product results through trial-and-error methods. The students also made careful decisions to meet the criteria, thereby choosing or preparing the correct casting mold, which will hold the concrete mixture.

The design criteria to create the respective sports products are elaborated hereafter:

1. Bowling ball-The group of students who chose to design a bowling ball considered certain conditions (refer to Table 2) to meet parameters such as surface smoothness, the ball's weight, and the distance traveled by it when rolled on a solid surface. The evaluators observed balls' surface smoothness by touching the balls and comparing them between that of each group to score the maximum. The entire construction of the bowling ball was wholly administered and carried out by the participants based on their judgment. They chose spherical mold and prepared concrete mixtures as per their choice of shape and ingredient proportions, although the facilitator pronounced the optimum ratio. They also performed casting, i.e., filled the molds with the fresh concrete mixtures and left them to dry for 1-2 weeks. Based on their judgment, they removed molds to carry out the curing process. The curing process is by which the concrete samples are hydrated to improve their strength. The students were solely responsible for deciding the curing time for concrete structures, which is an essential step in the construction because it affects the strength of the product. The students were also provided permission to smoothen the surface using any external tools such as a metal file rather than depending on the mold's texture, which naturally gives a smooth surface. This whole process was repeated if the end product broke or failed in meeting the diameter due to shrinkage. The ball was also dropped from a height multiple times to test its strength or success of the product. Once the ball met the required smoothness and weight, the test bowling ball was assessed by rolling through a V-shaped ramp to strike the bowling pins set across the lane. The wooden ramp was $1220 \mathrm{~mm}$ long and raised $400 \mathrm{~mm}$ on one end to achieve a reasonable ball 
speed (refer to Figure 2a). The ball had to "strike" between two edges spaced 600 $\mathrm{mm}$ apart at the end of the $3000 \mathrm{~mm}$ long lane. The test product, positioned at the top of a V-shaped ramp with no dust, was propelled down by gravity's force at room temperature onto a flat-surfaced lane. The ramp was made from two rectangular slabs of plywood, $440 \mathrm{~mm}$ wide, placed at an angle of 40 degrees from the flat surface (refer to Figure 2a). The product ball was rolled in two orientations as arbitrarily marked "mostly perpendicular" on the ball. For each orientation, the ball was tried twice to pass through the strike zone successfully;

2. Concrete boat-The design product alternative to the student's choice of "concrete bowling ball" was the concrete boat. The concrete boat was expected to meet certain assessment conditions (refer to Table 2) in parameters such as buoyancy, load-carrying capacity, and float time. Similar to the bowling ball design, the participants either made a mold out of raw materials such as foam, cardboard, wood, etc. or chose a mold with an appropriate size that could be immersed in a rectangular box of $40 \times 70$ $\times 40 \mathrm{~cm}^{3}$ filled three-quarter with water as a part of testing (refer to Figure $2 \mathrm{f}$ ). The students went under similar conditions in choosing the correct amount of concrete aggregates, casting, and curing identical to that of the bowling ball. The testing of the boat, however, was conducted in the water-filled tank as mentioned earlier and was carried out in three phases as follows:

- Assessment phase 1-The empty boat was placed in the water to examine its behavior under external factors; for example, the boat was tested to analyze its stability in the water and float freely for a minimum of $5 \mathrm{~s}$. The students also ensured that the boat was self-balanced while floating on the water (without touching the sides of the water-filled tank/box) (refer to Figure 2c);

- $\quad$ Assessment phase 2-It was assessed for another $60 \mathrm{~s}$ to monitor the internal parameters such as the concrete boat's quality in terms of leakage, water displacement, water absorption by the concrete walls, etc. While water leakage was observed visually, looking for traces of wetness in the interior of the boat, water displacement was monitored by examining the volume of the boat and the height by which the water rises in the tank. The interior of the boat was observed for wetness or moisture to test the absorption of concrete;

- Assessment condition 3-The boat would be lastly tested for its load-carrying capacity. The initial cargo added to the boat was $5 \mathrm{~g}$. Students incremented the weights only if the boat was in a stable condition without rocking to and fro in the tank. Cargo of $5 \mathrm{~g}$ was usually added in increments until the point when the vessel began to take on water. However, in some cases, students also used $10 \mathrm{~g}$ weights, depending upon the availability of weights. There was no minimum requirement for the cargo weight, and hence, the boat carrying maximum cargo without taking in water was considered for scoring the most in the score sheet. The leakages and similar defects observed in a few cases were fixed before the final trial for marking scores.

\subsubsection{Workshop 2}

The groups of students provided with Workshop 2 were monitored by the respective school to design a baseball or golf ball successfully. During the workshop, the students were familiarized with different sports materials and their properties, thereby cultivating their observational skills and analyzing capabilities. As the workshop progressed, the students performed hands-on experiments that provided a visual representation of scientific concepts such as friction, rebound, and energy transformations that are typically conveyed as regular school lectures. They were also acquainted with the different parameters that affected the functioning of the products. The various STEM activities (refer to Figure 1) carried out during the workshop is detailed as follows:

- Activity 1: Exploring rebound effect from different balls-As the workshop started with an ice-breaking activity, the students studied the rebound ability of different 
sports balls that were identical in shape and size, despite the materials, using a drop test (freely dropping from a specific height and measuring the rebound length);

- Activity 2: Hunting for different ball designs and materials-This activity, bolstering inquiry skills in high school participants, encouraged research on different sports materials such as cowhide, rubber, leather, etc. used in balls. Students studied different balls such as basketball, football, baseball, golf ball, etc. and hypothesized the purpose of each material as applied in a specific sports product. They also examined the design for each sports ball and compared its functionality. They interpreted the results mathematically in the form of graphs because STEM integration was encouraged throughout the activities.

- Activity 3: Investigating energy absorption of materials—During this activity, students familiarized themselves with energy absorption as they calculated the rebound height of a ball when impacted on different materials (floor tile, wooden board, carpet, felt) under freefall, thereby learning about energy absorption of the respective materials. Students also observed surface deformation in the case of different balls' impact. They also determined conclusions based on their acquired knowledge of the relationship between surface deformation and energy absorption;

- Activity 4: Comparing rolling friction on different surfaces-During this activity, students examined the behavior of different materials with respect to generating a frictional force on a rolling ball. Students tested different sports balls on each mat material one by one to draw out conclusions. They familiarized themselves with various frictional forces-kinetic, rolling, and static. They also interpreted results drawn from rolling ball surface and mat surface to be distinct from each other, and rolling action entirely depended on the materials.

Design project-This workshop focused on challenging the students to design sports products such as baseball and golf ball with materials that can provide the optimum results to meet several criteria (refer to Table 2). Since they invested a productive period for researching and understanding different materials during the workshop, they also performed binding and arranging different materials to obtain the desired outcomes, as in golf ball and baseball. The students evaluated their products' strengths and drawbacks, keeping records of every detail during their project work.

1. Baseball-The students who chose to design a baseball needed to overlook the evaluation criteria such as specificity in its diameter, weight, and the maximum ability to rebound on free fall. Since the regularity in the diameter of a handmade ball could not be guaranteed, the test ball diameter was measured using a Vernier scale (refer to Figure 2g). They transferred the knowledge acquired from the workshops to choose varied materials that could satisfy the requisites while testing the product balls. During the testing, the test baseball was freely dropped from a specific height of $1 \mathrm{~m}$ to measure the rebound height;

2. Golf ball-The golf ball challenge was staged in two sections, i.e., constructing the golf course pit and designing the golf ball for the students who chose the golf ball design project.

The students initially constructed a golf pit using synthetic materials considering rolling friction, rebound effect, and impact energy (refer to Figure 2f). They employed different materials, such as felt and synthetic grass in the pit area, to restrict a golf ball's rolling within a specific length (refer to Table 2).

While designing the golf ball, the participants considered different materials according to their behavior to accomplish specific scientific concepts that could satisfy the preset conditions (refer to Table 2). They chose the materials that led to building a smaller diameter ball with a specific weight producing lower rebound ability when compared to that of a baseball.

While testing, the ball was rolled down the tube (PVC tube, cut to $30 \mathrm{~cm}$ length) and placed fixed at an angle of 30 degrees (as shown in Figure 2e). The students determined the success of the ball, depending upon its ability to bounce once and clear the obstacle, 
roll across the green area, and stop within the target area (refer to Figure 2e). The test was repeated enough to obtain a $75 \%$ success rate for the respective product, i.e., out of four test attempts, the ball should be successful for three tries.

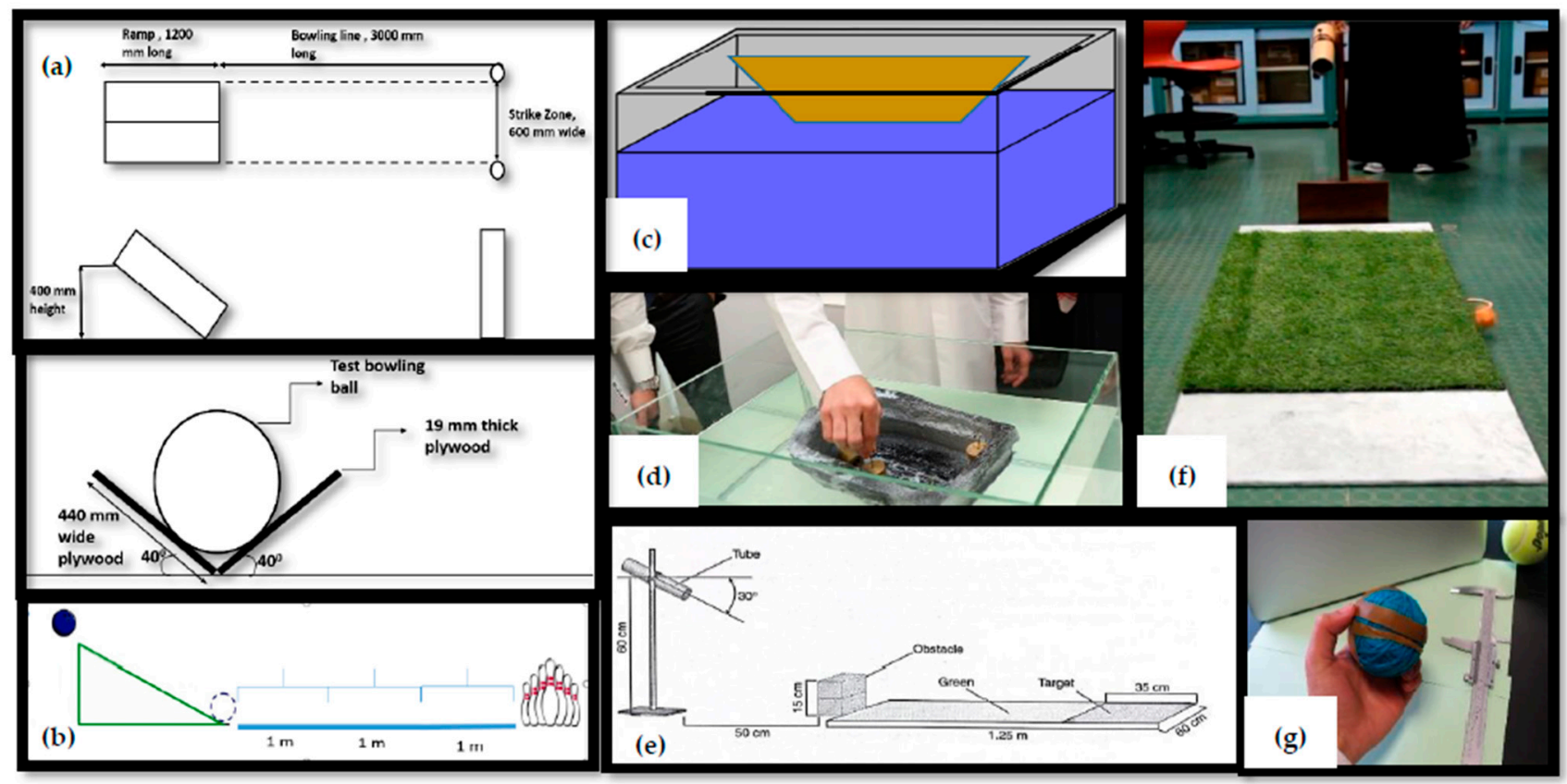

Figure 2. Schematic diagram of testing the different sports products. (a) An elevation view of the testing pits for the concrete bowling ball. (b) The front view of a schematic representation of the front view of a bowling ball testing kit. (c) The schematic representation of testing a concrete boat in a tank, three-quarter filled with water. (d) The concrete boat should be able to carry weight without sinking or any leakage. (e) The schematic diagram for the testing pit of a golf ball. The students prepare a golf course pit using different materials to test the rolling action of the golf ball. (f) A golf course is set up by the students to test their product golf balls considering the different parameters such as friction, rebound effect, etc. (g) A baseball diameter is tested using a Vernier scale.

Table 2. The list of parameters that need to be satisfied for excellent results.

\begin{tabular}{|c|c|c|}
\hline Product. & Parameter & Requirement \\
\hline \multirow{3}{*}{ Concrete Bowling ball } & Surface smoothness & Smooth surface \\
\hline & Weight of the ball & Less than $5.5 \mathrm{Kg}$ \\
\hline & Distance traveled & $3 \mathrm{~m}$ and hit the pins as shown in Figure $2 \mathrm{~b}$ \\
\hline \multirow{3}{*}{ Concrete Boat } & Buoyancy without weights (External factors) & Floating $<5 \mathrm{~s}$ \\
\hline & Buoyancy without weights (Internal factors) & Floating $<60 \mathrm{~s}$ \\
\hline & Loading capacity & Maximum weights \\
\hline \multirow{3}{*}{ Baseball } & Diameter & $7.3 \mathrm{~cm}$ to $7.6 \mathrm{~cm}$ \\
\hline & Weight & $142 \mathrm{~g}$ to $149 \mathrm{~g}$ \\
\hline & Ability to rebound & Maximum \\
\hline \multirow{3}{*}{ Golf ball } & Diameter & Between 4.5 and $5.5 \mathrm{~cm}$ \\
\hline & Ability to rebound & Bounce once and clear the obstacle \\
\hline & Ability to roll and stop (Friction) & Stop at target area \\
\hline
\end{tabular}

\subsection{Data Collection Methods}

Different forms of qualitative data were collected during the program, including facilitator observations, field notes, media (photos and videos), and student artifacts. The facilitator recorded daily observations immediately after the session that detailed student regular attendance, their learning outcomes, or cognitive skills acquired during each workshop session, and progress in their daily project work. She also recorded progress 
and obstacles during each workshop day, during which field notes, images, and videos were also taken. Questionnaires, as a quantitative data-collecting tool, were provided to the students before and after the workshop, later analyzed to understand the improvement in their attitudes toward STEM fields, the relevance, and STEM-driven careers. The questionnaires were adapted from previous research studies but were modified according to the study objectives [24]. Student artifacts/work that comprised of project presentations, sports products, and documentation video were also collected and presented as a part of a program-adjourning event, which was later utilized for the study. The two primary program evaluation tools that were implemented in data analysis are detailed below.

\subsubsection{Pre and Post Questionnaires}

The students were obliged to complete a set of study questionnaires (refer to Table S1 in Supplementary Materials) by pen and paper method to assess their attitude on science, technology, engineering, and mathematics (STEM) and its impact in the real world. The questionnaires consisted of multiple-choice questions that stemmed from the student opinion on STEM education, their career interests in scientific fields, and their skills. The students may recommend from four standards of agreement: "agree", "neutral", "disagree," and "do not know". The questionnaires were assessed using standard monitoring and evaluation (M\&E) procedures. The mean percentages of agreement of pre and post questionnaire results were compared in the procedure to analyze the outcome of the program. The questionnaire analysis used the Likert Scale (R. Likert, 1932), a one-dimensional psychometric response scale measuring a single trait implemented in questionnaires to achieve the participants' degree of agreement to a statement or set of statements. We used a 3-point scale ranging from "Agree" on one end to "Disagree" on the other with "Neutral" in the middle.

The questionnaires were pivotal in measuring their agreement on the importance of STEM fields, career aspirations, and their views toward independently performing a scientific experiment. Eventually, both the post and pre questionnaires were analyzed together to obtain the results.

\subsubsection{Evaluation of Project Presentation}

After completion, the products would be examined by external evaluators from sports facilities, academia, and leading economy driving industries. This evaluation was performed during a conference for two days to felicitate the student work. The evaluation was carried out in two stages-day 1 and day 2 . On day 1 , all the program participants were evaluated on their STEM competencies acquired through the sports product engineering project. They presented their project experience in a PowerPoint presentation, implementing digitalization in the process, and self-mentoring themselves in preparing for the evaluators' queries. The project presentation provided the students with opportunities to showcase their efforts. The examiners also challenged the students with questions that could assess their critical thinking and future outlook on their products.

Although each product had its respective testing criteria, as shown in Table 2, the evaluators also examined for other criteria, which were common to every design project. They had a separate rubric (refer to Table S2 in Supplementary Materials) for each student group presentation to rate the students' organizational ability, self-confidence, research methods employed for the design project, and critical thinking. The students were also rated for the quality of slides that were displayed as a part of their presentation. They were also scored for the students' creative display for choosing product mold, materials, and the quality of work exhibited in accomplishing each task.

The external examiners were from different backgrounds to perform a fair and overall assessment of the student work. For each design project, each sports product was examined on day 1 of the conference by a set of three judges. While one judge who held PhD qualifications and served as an academic in a university assessed the depth of scientific details and principles applied in the product, the other two, from the industry with 
backgrounds in engineering, focused on the presentation quality and the scope of the product in the future.

On the other hand, day 2 of the conference witnessed the participation of selected students who scored the maximum on day 1 evaluation. Only one group of participants from each category of sports product presented before the judges, who, this time, were from a wide range of fields that even included sports science specialty. There were five judges, one from academia, one from a sports training facility, and the other three from leading oil and gas industries. The first two judges were focused on science and sports, exploring the scientific knowledge and application of students. The latter three who hailed from the training and development department of heavy industries evaluated students ${ }^{\prime}$ competency display because they were more focused on the STEM skill development and presentation of the national participants.

\section{Results}

In this section, we lay out findings that include summaries of the journey of the students with each sports product based on the observation made by the facilitator during each session with the student. The findings drawn below are also based on their PowerPoint presentation from participant artifacts during their course-adjourning event. The students elaborated on their project journey and the number of trials and failures, providing the examiners the opportunity to picture the complete journey in the PowerPoint presentations. We also provided results drawn from statistical analysis of pre and post questionnaires that demonstrate the student attitudes toward STEM-driven careers and the importance of STEM in daily lives. According to conclusions in PowerPoint presentations, the participant students recorded their complete attempts, their reason for failure, and their successful attempts. These records were crucial in analyzing their problem-solving skills that provided adequate backings for facilitator observations.

\subsection{Analysis of Sports Products}

\subsubsection{Design Product 1}

Design product 1 chosen by a few participants of the concrete workshop was a concrete bowling ball that could roll on a solid dust-free surface and strike the pins set at the end of the course. The participants successfully constructed and designed bowling balls that met different criteria, such as surface smoothness, specific weight, and distance rolled, for the final evaluation (refer to Figure 3a). Since surface smoothness was one of the three requisites for successful completion as in Table 2, they chose suitable molds for casting concrete mixture that could provide a smooth texture, appropriate size, weight, and shape for the product. The design of the mold also influenced the resulting functioning of the product. The application of the right mold for casting a concrete mixture requires fine techniques and an understanding of texture, physical strength, and measurement. The students were ensured to choose a mold that can hold heavy concrete mixtures and can be easily broken once the concrete is ready. While some students used volleyball as a mold, most of the students used spherical light bulbs made from plastic or glass. 


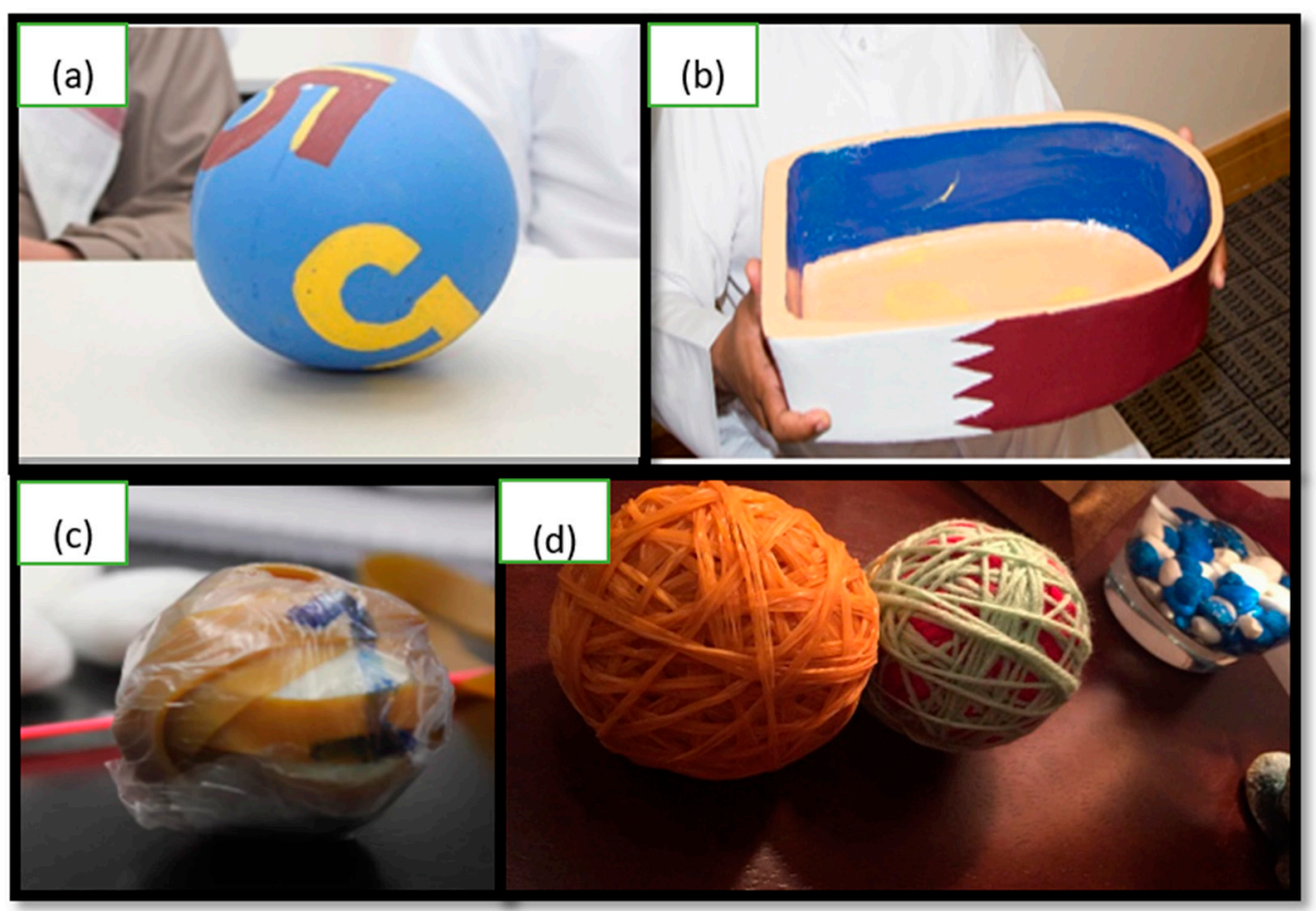

Figure 3. Examples of students' sports products that were displayed during the program- adjourning event. (a) A sample concrete boat is made as an engineering design challenge by the students applying knowledge acquired. (b) The students applying knowledge acquired during the concrete workshop session make a sample concrete bowling ball as an engineering design challenge. (c) A golf ball made by the participant groups is illustrated through the images. The students transfer knowledge acquired during the sports material workshop session by making a sample golf ball as an engineering design challenge. (d) Different samples of baseballs as developed by participant students. The latter images also showcase the binding of the materials in different patterns.

Another criterion of specific weight was also met by the students' different measures to accomplish the task. For appropriate weights, students considered different reinforcing materials that could contribute to balancing the weight and strength, and quality of the product (refer to Figure S1 in Supplementary Materials). Moreover, restricting the weight of the ball according to the evaluation criteria was a major challenge as they repeatedly tested various combinations of concrete mixture ingredients to obtain the desired weight within the specific diameter. It was completely students' choice to fix the composition of concrete ingredients, and thus, they had to ensure that they had enough concrete to fill the mold.

Since the students were faced with multiple conditions, i.e., restricting weight as in Table 2 and maintaining a spherical shape simultaneously, the assignment nurtured their thinking capacity and solving capabilities, in turn enhancing their critical thinking and problem-solving skills. The students also familiarized themselves with the impact and different techniques for proper mixing, as in the boat challenge, to obtain the desired texture and consistency without any lumps. The finished product was tested by dropping freely down the ramp, set $3 \mathrm{~m}$ away from the bowling pins (refer to Figure $2 \mathrm{~b}$ ). While rolling the ball on the ground, the students identified the possible flaws in the product that might have resulted from improper texture, weight, or shape depending on the rolling action of the balls. The testing of bowling balls fascinated the students as they indulged in "play and learn," thereby engaging actively in the program.

Table 3 implicates the course of two random groups $(1 \mathrm{a}, 1 \mathrm{~b})$ who applied the trialand-error method to create the final successful product, which was obtained from student records in PowerPoint presentations. This table also provides insight into developing their reasoning and problem-solving tactics as they carried different strategies to accomplish 
the task. They were also challenged while testing their product, concrete ball, by dropping the finished product freely down a ramp set $3 \mathrm{~m}$ away from the bowling pins (refer to Figure S1 in Supplementary Materials).

Table 3. The information on two random groups attempting design product 1 .

\begin{tabular}{|c|c|c|c|c|c|}
\hline Sample Groups & Sample Products & Trial Count & & $\begin{array}{c}\text { Reason of Failure (Refer to Table } 2 \text { for } \\
\text { Criteria) }\end{array}$ & Reason for Success \\
\hline Group 1a & & two attempts & & The mold used was big. & $\begin{array}{l}\text { Changed the mold to } \\
\text { make a smaller ball }\end{array}$ \\
\hline Group 1b & Concrete bowling ball & four attempts & $\begin{array}{l}1 . \\
2 . \\
3 .\end{array}$ & $\begin{array}{l}\text { The size of the ball does not meet the } \\
\text { competition's requirements. } \\
\text { The product was heavier than the weight } \\
\text { limit, which is } 5.5 \mathrm{~kg} \text { and had many } \\
\text { holes that were difficult to remove. } \\
\text { Adding the paper balls made it easier to } \\
\text { break as they had a lot of cracks and took a } \\
\text { lot of space, which made the bowling ball } \\
\text { weaker; after several tests, It got broken. }\end{array}$ & $\begin{array}{l}\text { Added a plastic ball at the } \\
\text { core that balanced the } \\
\text { weight required keeping } \\
\text { the diameter under the } \\
\text { condition. }\end{array}$ \\
\hline
\end{tabular}

The students assigned with the bowling ball challenge hardly had opportunities to vary the design of their product regarding the shape, owing to the fixed spherical shape and diameter, in contrast to the concrete boat challenge. Hence, most of their creativity was exhibited in designing the final product. They gave careful consideration in painting their products (Figure S1 in Supplementary Materials) and presenting it to the judges as creativity was one of the criteria in the rubric (refer to Table S2 in Supplementary Materials) set for them.

\subsubsection{Design Product 2}

Design product 2 , chosen by some of the concrete workshop participants, was a concrete boat capable of floating and carrying cargo. The students exhibited a wide caliber of proficiency while designing boats that satisfied the buoyancy and load carrying capacity (refer to Figure $3 b$ ). They were examined for their product quality in terms of scientific application and various skillset as they paced from the basic steps of the engineering challenge to successfully presenting a fully functional product. The resulting boats also supported the expected quality of concrete that displayed efficiency in terms of parameters such as workability, durability, strength, cost, and finished appearance. The quality assurance of the product was solely attributed to the student competencies, which ensured not to overlook factors such as the ratio of ingredients, mixing of the ingredients, handling of the fresh concrete, and finally, placing for curing until the ultimate strength was achieved (refer to Figure S2 in Supplementary Materials). Once the concrete boats exhibited fine strength and texture, it was tested by floating in water-filled tanks. In the case of failures such as leakage or inability to float or/and carry weight, the product was subjected to reconstruction or improvisations and retesting.

The students also exhibited remarkable problem-solving skills as they followed a trial-and-error method to construct the sports product and optimize the experiment in a scientific method. From Table 4, it was identifiable that they were able to recognize the reasons for failure and success distinctly, for example, cracks, leakages, inability to float, or even concrete collapsing on mold dismantling. Some groups of students attempted several trials, ranging from a minimum of two to an utmost nine trials, in accomplishing the nearest best solution. Table 4 provides the course of two random groups, $2 \mathrm{a}$ and $2 \mathrm{~b}$, with their number of attempts and improvisations as represented in PowerPoint presentations. Eventually, this concrete boat challenge was also suitable for drawing their creativity out. It encouraged the students to display artistic talent in addition to STEM learning while sketching their product structure or painting the finished product (refer to Figure S2 in Supplementary Materials). 
Table 4. The information on two random groups attempting design product 2 .

\begin{tabular}{|c|c|c|c|c|c|c|}
\hline $\begin{array}{l}\text { Sample } \\
\text { Groups }\end{array}$ & $\begin{array}{l}\text { Sample } \\
\text { Products }\end{array}$ & Trial Count & \multicolumn{2}{|r|}{ Reason of Failure (Refer Table 2 for Criteria) } & \multicolumn{2}{|r|}{ Reason for Success } \\
\hline Group 2a & \multirow[b]{2}{*}{ Concrete Boat } & three attempts & 1. & $\begin{array}{l}\text { Amount of Cement is less than the fly } \\
\text { ash and silica. } \\
\text { The boat design was not uniform }\end{array}$ & $\begin{array}{l}1 . \\
2 .\end{array}$ & $\begin{array}{l}\text { The ratio of concrete materials } \\
\text { was appropriate. } \\
\text { The design was modified, and } \\
\text { the boat floated and held weight. }\end{array}$ \\
\hline Group $2 b$ & & three attempts & 2. & $\begin{array}{l}\text { The ratio of concrete aggregates was not } \\
\text { appropriate. } \\
\text { The reinforcing material for the concrete } \\
\text { could not hold as the group tried a green } \\
\text { concrete mixture. }\end{array}$ & & $\begin{array}{l}\text { Succeeded in the right ratio of } \\
\text { materials. }\end{array}$ \\
\hline
\end{tabular}

\subsubsection{Design Product 3}

Design product 3 , chosen by some of the sports materials workshop students, was a golf ball conditioned to pass an obstacle, rolling down the course to stop at a certain point.

The golf ball challenge was carried out in two distinct phases: Phase 1-constructing the golf course pit and Phase 2-designing a golf ball.

- $\quad$ Phase 1-The students designed and constructed a miniature golf course pit (refer to Figure S3 in Supplementary Materials) so that they could test their product golf balls. They set up a course pit, as shown in Figure 2e, according to the required parameters and implemented synthetic materials that contributed to the effective testing of the sports products. The students also applied the knowledge acquired during the sports materials workshop in successfully designing and building the pit. They constructed the course pit using felt and synthetic grass sheet made from polypropylene, polyethylene, and nylon. They were successful in restricting their product balls within the specified length and width of the designed course. While constructing the course pit, they used a standard golf ball for testing the course pit in meeting the adequate condition. The students tested different materials to lay on the pit and rolled the ball down the PVC tube to pass the obstacle, as shown in Figure 2e. The expected functionality of the laid materials was to restrict the rolling of the ball to a specific length of $1.25 \mathrm{~m}$, as shown in Figure $2 \mathrm{~b}$.

- $\quad$ Phase 2-The students successfully designed and tested golf balls (refer to Figure 3c) that were able to satisfy the preset conditions (refer to Table 2). They chose optimum materials that contributed to accomplishing their design criteria, specifically balancing the required rebound ability to cross the obstacle and the desired diameter. Evaluating their techniques, the students also considered the efficiency of the ball's binding process as crucial in obtaining the best results. If the ball was not tightly bound, the rebound results may vary due to the irregularity in its shape and uneven energy transfer. The students also experimented in binding and varying techniques resulting in varying outcomes, as shown in Figure 3c. They studied and applied different scientific principles such as the energy of absorption of different materials when subjected to impact on solid ground.

Resultantly, students applied trial-and-error methods to solve their task, as similar to the other three design product challenges (refer to Table 5), which were retrieved from PowerPoint presentations. They could clearly identify the shortcomings, assess their product, and apply the acquired knowledge to create a successful outcome. In some cases, the students also reattempted to improve the results of the product, even though the first attempt did clear the task. This also detailed their attitude of creating room for continuous self-improvement. In due process, they also bolstered inquiry skills as they continually asked questions such as, "what are the factors" or "what are the materials" for deriving a successful output. Table 5 implicates the course of two random groups who applied the trial-and-error method to create the final successful product. 
Table 5. The information on two random groups attempting design product 3 .

\begin{tabular}{|c|c|c|c|c|}
\hline $\begin{array}{l}\text { Sample } \\
\text { Groups }\end{array}$ & $\begin{array}{l}\text { Sample } \\
\text { Products }\end{array}$ & Trial Count & Reason of Failure (Refer to Table 2 for Criteria) & Reason for Success \\
\hline Group 3a & Colf hall & two attempts & $\begin{array}{l}\text { The rebound was not enough to jump the obstacle } \\
\text { (refer to Figure } 2 \mathrm{e} \text { ) }\end{array}$ & $\begin{array}{l}\text { A rubber core was made using glue to } \\
\text { create the bouncy effect without } \\
\text { increasing weight }\end{array}$ \\
\hline Group $3 b$ & Golf ball & two attempts & $\begin{array}{l}\text { The golf ball made during the first attempt was } \\
\text { considered a failure because the students made a } \\
\text { better product that gave better results }\end{array}$ & Used different ratios of the materials. \\
\hline
\end{tabular}

The students' creativity was also tested in their choice of materials (as in Figure 3c) used in designing the balls to obtain the desired weight, diameter, and rebound properties. They experimented in applying different materials, such as glue, rubber bands, bouncy balls, etc., to construct either the outer layers or the inner core material, thereby testing their limits to creative imagination.

\subsubsection{Design Product 4}

Design product 4 , chosen by some group of Workshop 2 participants, was a baseball exhibiting a considerable rebound height. The students were focused on choosing materials that contributed to accomplishing the design criteria, specifically the rebound ability. They sandwiched different materials, such as rubber, yarn, fabric, etc., depending upon their weight and rebound ability to construct a ball structure. The order of placing different materials was also varied, looking for the best rebound effect. In some cases, they varied the usage of rubber material, for example, they used a rubber ball as the inner core as well wrapped rubber bands outside to form the outer core. In some cases, they also put forth innovative ideas such as a plastic mini ball as a core, contributing to less weight and best rebound results under restricted diameter. The students also applied techniques while binding the materials that contributed to the product's different properties (refer to Figure 3d) such as spherical shape and rebound effect, etc. A loosely bound ball was observed to rebound less when compared to a tightly bound ball as the ball deformation was varied on-ground impact and energy was distributed unevenly. These observations inspired students to understand basic concepts of science in a better way. The students tested their completed baseball products (refer to Figure 3d) by freely dropping them from a height of $1 \mathrm{~m}$, thereby addressing the product's possible flaws. The students also considered the scientific facts, e.g., how the efficiency of binding contributes to the fineness of the ball surface. The participants also tried different binding patterns and materials, as shown in Figure 3d, which influenced the outcome of each product.

The students also solved their challenges in obtaining a balanced baseball with the desired weight and diameter by implementing the trial-and-error method (refer to Table 6, according to the conclusions from PowerPoint presentations). Moreover, as they introduced unique solutions to solve the problem, portraying the creative side of their cognizance, they referred to materials such as cowhide, yarn, etc. that could help solve the task drawing out the creative collaboration within the group. Table 6 implicates the details of two random groups who applied the trial-and-error method to create the final successful product.

Table 6. The information on two random groups attempting design product 4 .

\begin{tabular}{|c|c|c|c|c|}
\hline $\begin{array}{l}\text { Sample } \\
\text { Groups }\end{array}$ & $\begin{array}{l}\text { Sample } \\
\text { Products }\end{array}$ & Trial Count & Reason of Failure (Refer to Table 2 for Criteria) & Reason for Success \\
\hline Group 4a & Baseball & $\begin{array}{l}\text { three } \\
\text { attempts }\end{array}$ & $\begin{array}{l}\text { The bouncy ball (the core) was small, so the } \\
\text { diameter was big with the right weight. } \\
\text { The final surface was not regular and was not } \\
\text { smooth enough. }\end{array}$ & $\begin{array}{l}\text { Changed materials by using a bigger } \\
\text { bouncy ball, cowhide, yarns, and glue. }\end{array}$ \\
\hline Group $4 b$ & & two attempts & The rebound was less. & $\begin{array}{l}\text { The binding of the materials was } \\
\text { made stronger. }\end{array}$ \\
\hline
\end{tabular}




\subsection{Demonstration and Presentation of Design Projects}

A conference was organized at the end of the program as an adjourning event for two days, displaying and examining the students' final products in the presence of an evaluation panel. The panel included leaders from industries (refer to Figure 4) in the STEM domains. Day 1 witnessed all groups' participation, portraying their program journey in PowerPoint presentations, videos, and photographs. They presented their products in the presence of the judges to demonstrate their accomplishments. On day 2, three winning groups (one from each sports product category) displayed their products to a different set of panels that comprised leaders from the best sports facility and community in Qatar.

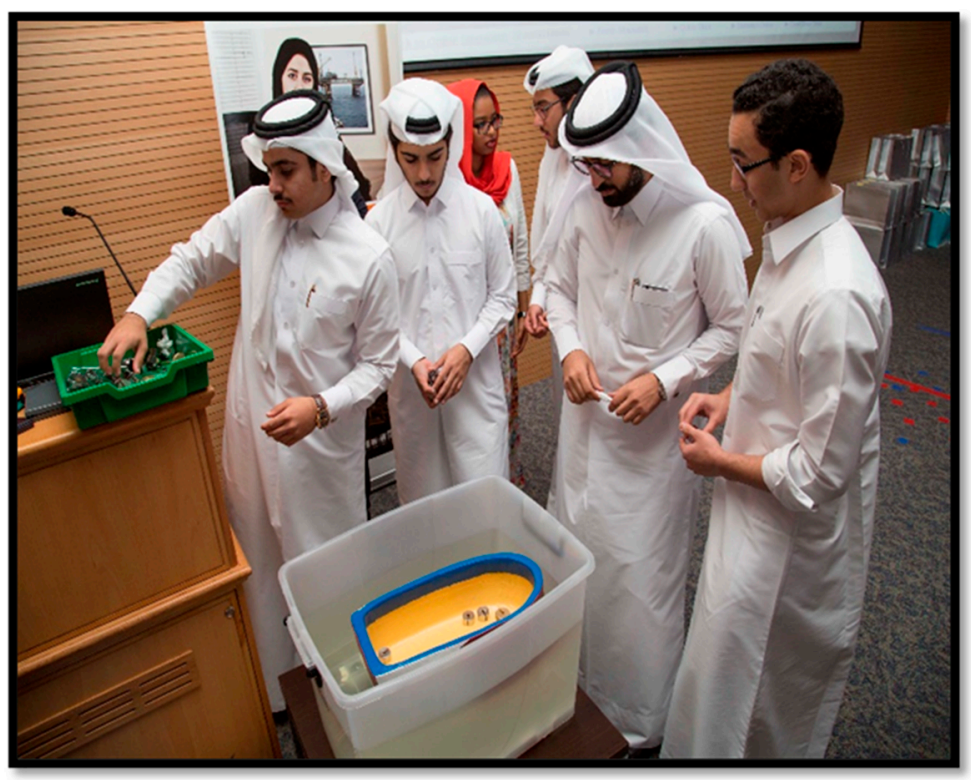

(a)

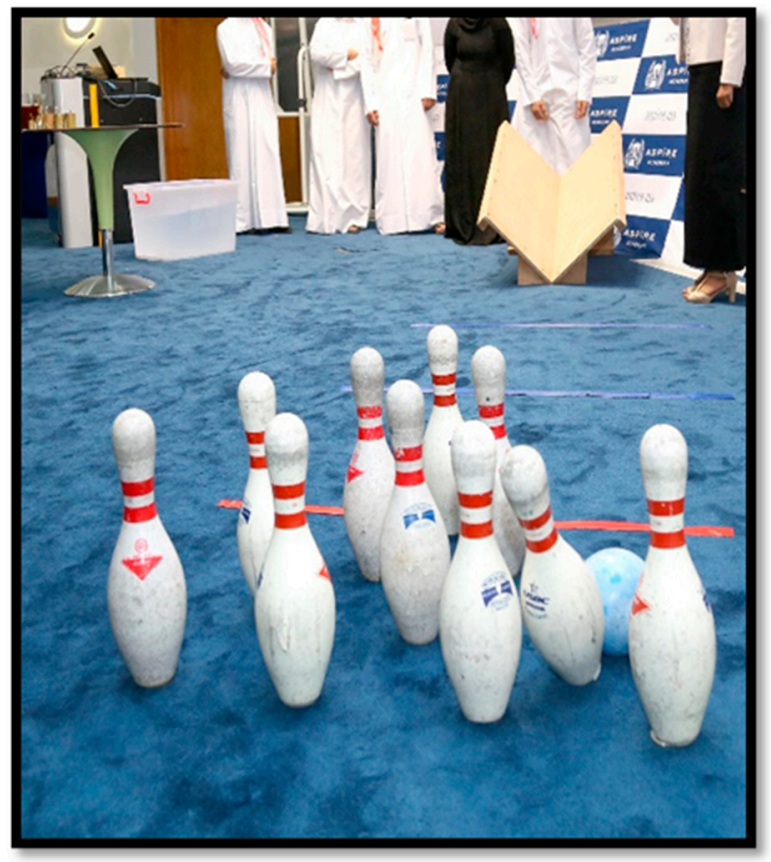

(b)

Figure 4. Students displaying their products for evaluation. Students in the image (a) are testing their concrete boat by incrementing the weights in the boat thereby testing its load-carrying capacity. (b) Bowling pins are laid $3 \mathrm{~m}$ away from the ramp for the evaluation of the bowling ball.

Before the evaluation was held on a public platform in the presence of a larger audience, the students improved their oration, body language, public speaking confidence, and vocabulary. As they presented their products to the panel, the students displayed their presentation skills along with the communication dispositions. The participants were assessed critically for their organizational ability, research methods implementation, and creative collaboration as they presented their project experience. They integrally replied to the judges' queries with confidence, proving their skill-based improvement.

\subsection{Descriptive Statistical Analysis}

Analysis of the study was quantitatively carried out by conducting pre- and postworkshop surveys. The study clearly manifested the increment in students' interest in an interactive STEM curriculum. The analysis also reported considerable growth in their self-efficacy and innovative skills along with their positive inclination toward STEM, both generally and career wise. The pre-post questionnaire analysis of four objective study indicators directed toward students' STEM attitudes was demonstrated, as in Figure 5 and Table 7. The students' pre- and post-questionnaire results were statistically calculated and analyzed using the $t$-test statistical calculator to determine the program effectiveness indicators ( $p$-value, $\mathrm{t}$ value, mean differences). The $p$-value for the $t$-test conducted for all 
five cycles was less than 0.05 , as in ideal condition (except for the fourth cycle $p=0.229$ ). Hence, the results indicate that there was a significant difference between the two sets of data means (pre and post means), concluding the considerable improvement of their attitudes after the program (refer to Table 7 and Figure 5, as well as detailed Tables S3 to S12 in Supplementary Materials). In addition, considering the $t$ value for the confidence interval ( $t \leq 2.262$ to reject the null hypothesis), there was strong evidence (except for the fourth cycle $t=1.22$ ) to validate that the experiment falls under the range of $95 \%$ confidence interval (95\% CI). The 95\% confidence interval (95\% CI) holds a key factor in determining the program's constructive role in the student outlooks toward STEM. For the given set of data, the outcome improved scores, on average, by an approximate value of 0.8 . The following STEM interest indicators were used to perform the $t$-test analysis:

- We live in a better world because of science, technology, engineering, and math (STEM);

- Learning science, technology, engineering, and math (STEM) is essential for my future success;

- I would like to have a career as a scientist or researcher;

- I have the skills to implement a scientific experiment.

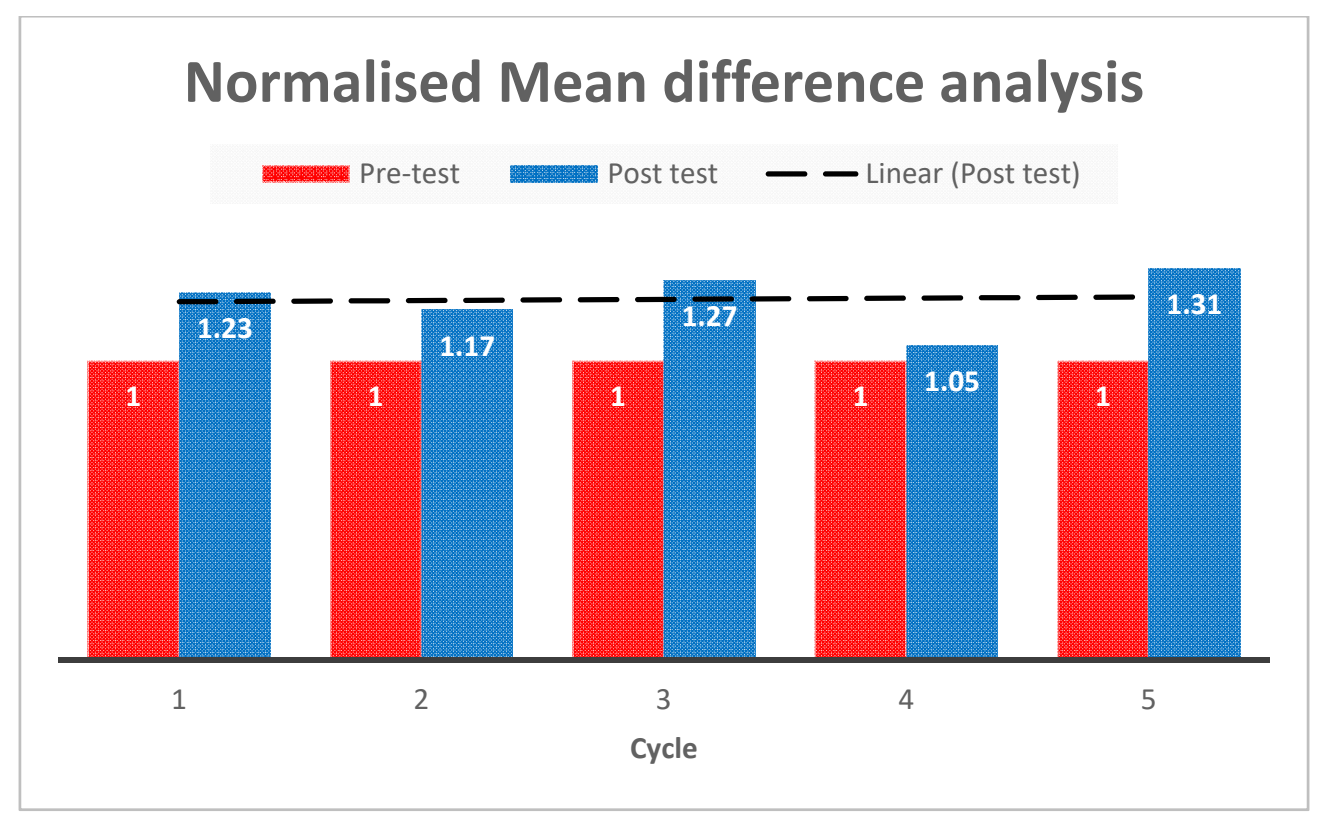

Figure 5. Normalized pre-test and post-test mean difference comparison of the student population for five cycles $(n=248)$. The blue line and red line display the pre-test mean and post-test mean percentages of the questionnaire analysis data collected from the five-year experiment, respectively. It is evident that despite the results drawn from the fourth cycle, the program proves to be effective in improving students' attitudes by a significant margin.

Table 7. "Science in Sports" (SIS) cycles by $t$-test analysis $(n=248)$. The " $n$ " for each cycle is less than the initial number as stated in Table 1, as the analysis is performed only for participants who have performed both pre-test and post-test questionnaires.

\begin{tabular}{ccccccc}
\hline \multirow{2}{*}{ Cycle } & \multicolumn{3}{c}{ Statistics } & \multicolumn{3}{c}{ Sample Tests } \\
\cline { 2 - 7 } & Participants N & $\begin{array}{c}\text { Pretest Mean } \\
\text { (SD) }\end{array}$ & $\begin{array}{c}\text { Posttest Mean } \\
\text { (SD) }\end{array}$ & $\begin{array}{c}\text { Mean Diff } \\
\text { (SD) }\end{array}$ & $\boldsymbol{t}$ Value & $p$-Value \\
\hline 1st & 51 & $3.07(0.932)$ & $3.79(0.865)$ & $0.730(1.185)$ & 4.4 & 0.000 \\
2nd & 56 & $3.38(1.205)$ & $3.98(1.032)$ & $0.603(1.680)$ & 2.68 & 0.01 \\
3rd & 35 & $2.98(0.570)$ & $3.81(0.900)$ & $0.836(0.889)$ & 5.56 & 0.000 \\
4th & 52 & $3.46(0.865)$ & $3.66(0.913)$ & $0.202(1.195)$ & 1.22 & 0.229 \\
5th & 54 & $2.31(0.746)$ & $3.03(0.693)$ & $0.722(0.757)$ & 7.02 & 0.000 \\
\hline
\end{tabular}


While analyzing the data of student attitude differences between pre-program and post-program, we observed an increasing trend line from cycle 1 to cycle 5 . However, we noticed that the dips in the graph areas for cycle 4 and cycle 3 were because those data correspond to students from urban schools. We deduced that students in urban schools are already familiarized with STEM relevance and this had an impact on having less difference between pre- and post-program attitudes. They initially developed high individual opinions toward STEM fields. However, as we started experimenting the study on students from rural areas, we observed that there exists a clear distinction of improvement in their attitudes post program.

\section{Discussion}

The sports-based program has conferred productive insight into students' cognitive skills development and their attitudes toward STEM domains and aspirations. The SIS program has positively influenced participant students' cognitive development because they successfully designed their sports products. This section explored program outcomes, the improvement in students' learning, sense of efficacy, and the ability to solve problems. The three forms of data for evidence in assessing STEM workshop outcomes, design products, and strength, weakness, opportunities, and threats (SWOT) analysis are the following: (a) workshop outcomes (based on facilitator observation); (b) facilitator's assessments of students' work (design products); and (c) demonstrations of student dispositions (e.g., presentations, facilitator observations, school teachers). We hereafter discuss the outcomes in detail.

\subsection{STEM Workshop Outcomes}

The STEM workshop conducted during the one week witnessed students' active learning involvement in various sports-driven activities cultivating inquiry, research, logical reasoning, and creativity. The research-directed activity was successfully administered to implement digital tools in their inquiry-based learning process, improving their scientific knowledge in the subject context and productively implementing technology for learning. Experiencing the various hands-on scientific activities, the students enhanced their technical knowledge in terms of precision, accuracy, and measurement, later applied in the design project challenge. The diversity in the scientific experiments and vitality of the sports offered the students positive settings, henceforth cultivating curiosity, creative engagement, and appreciation toward science. The students were seen to be entirely fascinated by exploring the interconnection between sports and engineering, hence engaging keenly in understanding the underlying scientific concepts in sports and thereby addressing STEM learning. The activities also helped them apply different strategies and effectively transfer the acquired knowledge from the workshops to meet the engineering design challenge criteria. The four activities from Workshop 1 were crucial in developing scientific interest because they explored the scientific subject content aiming toward a design goal in informal learning set up $[28,29]$. As the students learned the necessary knowledge to construct a fail-proof concrete object, they were experiencing learning through hands-on activities similar to the studies conducted prior [22]. For the design project, they integrated scientific content such as floating conditions, Archimedes principle, rolling friction, and frictional interaction between bowling lane surface and ball surface from their regular school lessons into the workshop outcomes to design the ultimate sports product [30].

On the other hand, Workshop 2 acquainted them with visual information and handson experience on the rebound behavior and coefficient of restitution, included in their school physics curriculum, however, through the introduction of sports products such as baseball, basketball, etc., which was a relatively new experience. Workshop 2 also provided a novel approach to teaching the energy absorption of different materials such as wood, cow-hide leather, rubber, yarn, etc. through a hands-on approach, which was easier for the students to apply in their design project. 
The cognitive development of the students was the main focus of designing and constructing the sports product. On cognitive measures, students enhance their fundamental thinking skills such as inquiry, hypothetic deductive reasoning, comparing and contrasting, and question generating similar to that of workshop activities as observed by previous researchers $[25,31]$. These skills were embedded in the sports design products, wherein the students nurtured them as they needed to make choices that led to accomplishing their tasks, such as choosing different weight compositions of concrete ingredients or choosing viable materials. Even while choosing the materials, there were different levels of decision making they had to partake, considering weight or surface absorption or any other parameters. Many of the researchers employ these methods in science teaching under the experiential learning process $[22,32,33]$. The evidence demonstrating the above conclusive results was portrayed in the Results Section analyzing different sports products.

While examining the workshop outcomes and addressing RQ 1 and 2, the $t$-test analysis was conducted on the 248 participants, providing mathematical representations of the difference in the students' attitudes displayed pre and post workshop. T-test was conducted on five batches of students, who participated in the SIS program in consecutive years (2012-2017). As shown in Figure 5, a positively increasing trend line displaying the significant difference between pre-test mean and post-test mean shows the effect of similar STEM mentoring programs, capable of improving the STEM preferences in school students. In addition, the trend shows that the study results fall under a $95 \%$ confidence interval, validating the success of the experiment. The outcomes from the success of the product development and application of different STEM methods along with the statistical representations from Table 7 clearly directed toward the RQs, 1 and 2, "Did the student understand the importance of STEM by experiencing science through sports product engineering?" and "Will the student consider STEM driven career resultantly in the future?", respectively. Their future aspirations were dominantly influenced by the program, as demonstrated in Table 7.

\subsection{A Facilitator's Outlook on Student Journey with the Design Products}

The facilitator keenly observed the growth of students and their dispositions from the first day of the workshop. The field notes and daily reports on the different student groups provided detailed analysis results on their display of diverse STEM dispositions such as problem solving and logical reasoning. Moreover, the facilitator also noticed the progress in their self-confidence as they creatively collaborated with peers and mentors (facilitator and schoolteacher). Their journey with reference to the design product is detailed hereafter.

The facilitator recognized the improvement in students' learning behavior while analyzing the different reasons for failures during the construction of the bowling ball. The students were able to assess the variant flaws accurately either during mold selection, product finishing (removing mold from the dried concrete product), or product testing. In case of unsuccessful attempts, they observed that the students could attribute the cause of failure to valid scientific reasons. They observed that students frequently burst with quick queries, "why" and "what if" much more often than the regular workshop days because they were impatient to solve their challenge.

As the students decided the mold (shape), proportion, and weight of concrete ingredients (appropriate weight), and finish the final product with adequate testing, the facilitator observed pride and satisfaction in achieving a target successfully. It was observed that some of the groups failed during the first attempt due to poor mold choices. For example, while choosing the mold, they attempted to introduce novel ideas such as paper mold, which did not have the strength to hold the concrete mixture, thereby collapsing the end product (as shown in Figure S1 in Supplementary Materials). Apart from choosing mold and making decisions on proper aggregate composition, the groups considered adequate atmospheric conditions to ensure the finished concrete models' essential curing. They performed curing to prolong the hydration (chemical reaction with water molecules) of cement in the concrete structure to develop calcium hydrate silicate gel, a strong binding 
material to reduce porosity and increase concrete density. This process was crucial in preventing surface crumble or sample breakage. Students also acknowledged the reason for failure in some cases due to breakage or cracks as the lack of providing adequate curing time. The main goal achieved in leading the students through the activities was to ensure that they acquire scientific knowledge in practice rather than a one-sided instructional delivery [34]. These experiences were acting as intrinsic motivators for the students' active participation $[20,35]$. In due process, the students also invested in learning the scientific principles from sports product engineering, which was an additional practice for the students. They investigated different factors that affected the desired level of "skid-hook-roll" action during the testing process, which was crucial in hitting the pins (Freeman and Hatfield, 2018). It was also observed that the testing of the products offered a consolidated "play-and-learn" opportunity to the participants, enhancing their interest in STEM integration in their regular school driven science concepts. As in the case of bowling ball, they acquainted themselves on the scientific principles such as rolling friction and frictional interaction between lane surface and ball surface, improved by polishing the ball surface to a "glossy" finish, which guaranteed a longer skid and a sharper hook in the back end for the best results (Freeman and Hatfield, 2018). They also correlated the concept of friction, inelastic deformation, and energy conservation (the kinetic energy of the rolling ball was converted in contact with the pins), and as in the case of concrete boats, buoyancy, density, and material compactness were visually experienced through this learning method.

The students were provided with experience studying and testing multiple materials, such as concrete materials, wood, carpet padding, felt, Astroturf, foam rubber, acoustic tiles, linoleum, shag carpet, etc., in laying out the course pit material or choosing materials, as in the baseball challenge. Since this method of bringing the students into the experimental field through an integrated STEM approach and providing opportunities for intermingling with peers successfully enhances STEM literacy, the facilitator found an enhanced level of motivation in the students to address the challenges [30]. Participants also had a wide experience while experimenting with yarn, rubber bands and shreds, felt, fabric scraps, aluminum foil, glue, etc. while constructing a ball that could deliver the desired rebound height and rolling action.

Interestingly, this study witnessed the effective implementation of mathematical concepts such as applied geometry, measurement, ratio, and proportion for studying the physical behavior of concrete under varying conditions, with STEM learning being integrated into the procedure, as effective as in previous studies $[5,29,30]$. The students applied different mathematical expressions that include density (D), where $\mathrm{D}=$ mass/volume, which was relevant to sketch the shape of the boat with increased length, breadth, height ratio, thereby increasing the volume to be greater than the mass of the boat. They learned and applied the coefficient of rolling friction (CR) and coefficient of restitution (COR) formulas in the case of products that involved ball action (baseball, golfball and bowling ball); $\mathrm{COR}=\sqrt{ }$ height of rebound $/ \sqrt{ }$ drop height and $\mathrm{CR}, \mu=$ rebound height/distance traveled by the ball.

The facilitator put forward the challenge of building the test golf course pit to the entire batch of participants in the respective school to exploit their problem-solving skills, knowledge transfer capability, teamwork, leadership, and creative collaboration. However, because this was a collaborative endeavor, it was easy for the facilitator to understand the students' development in leadership and peer collaboration. The golf ball challenge provides an excellent "play-and-learn" opportunity for the students because they learned basic science concepts such as rolling friction, rebound, and energy absorption of materials through integrated STEM-driven plays. They explored the interplay between sports and science, attracting the students and influencing their desire for science and STEM subjects. The design challenge has played an imperative role in amplifying science's perception as a positive, "fun" experience. These observations made by the facilitator based on the validated responses from the students addressed the RQ3 research question, "Were the students able to understand and correlate scientific principles to the applications in daily 
life?". The workshops provided ample grounds for the students to understand the scientific principles while the students employed diverse tactics to solve the problems from a STEM perspective during the trial-and-error method.

The facilitator recalled that students fostered their creativity from effective peer collaboration, apart from critical thinking and reasoning skills as they designed each product's shape and dimensions, reinforcing previous studies [34]. They also noticed that the students, in the process, gained learning outcomes in regard to the application of scientific concepts such as in sports-based real-life scenarios. Creative designing was observed as the students had to limit boat size to be immersed in the testing tank. These creative expressions were also applied during the construction of the mold because some participant groups constructed the mold for the boat from raw materials such as foam sheet, cardboard, or wood (refer to Figure S2 in Supplementary Materials), while the other groups opted for readily available toy boat molds (refer to Figure S2 in Supplementary Materials).

\subsection{Discussion on Schoolteachers' Observations}

The qualitative responses from schoolteachers and students substantiate their enthusiasm for the program. Teachers especially liked the variety of inquiry-based activities and resources provided in the workshop. They observed positive responses in their students with increased analytical thinking. Teachers also regarded the workshops and design challenges as an inspiring experience that nurtured students' interest in STEM. School teachers also validated that the students were enthusiastic during hands-on activities because they were involved in constructing sports products [36,37]. Due to their cultural orientation toward sports, participants also clearly exhibited their enthusiasm for sports-based engineering assignments. Male participants typically showed less interest in writing activities, as recalled by the teacher, in contrast to hands-on activities that included measurement, preparing concrete mixtures, and testing the products. This type of behavioral differences by different validating researches $[12,38]$. They generally were motivated during teamwork to work zealously on the products and even collaborated cordially with the facilitator.

\subsection{Strength, Weakness, Opportunities, and Threats (SWOT) Analysis}

The facilitator well examined the experimental methods and results to develop a SWOT analysis matrix. The SWOT analysis laid out the key observations that pointed out strengths, weaknesses, and future possibilities in the study.

\subsubsection{Strengths and Weaknesses}

The layout and execution of activities that led the students to design a sports product effectively were pointed out to be a strength. The layout of activities clearly manifested the necessary aid for the students in accomplishing their target objectives. The inquiry-based methodology in the activities opening into a trial-and-error experimental method in satisfying a set of conditions led the students to examine their project from their perspectives, thereby elaborating their thinking capability. In addition, the study methods' creative collaboration was also considered a plus point for the research study.

While assessing the weaknesses, it was observed that the experiment chose a random selection of sports products that were easy to construct in terms of high school students' competency. Although the study was conducted through a well-laid out activity plan leading to design challenges, the relationship between the four sports products was not clearly established. However, this shortcoming was not addressed before the students because they were introduced to a STEM workshop, which by the end, led to the design of two sports products that fall under the same category. The weakness that was highlighted by the facilitator was its limitation in assessing the student competencies using an internationally standardized testing rubric, which will be further considered for future research. 


\subsubsection{Opportunities and Threats}

Taking into account the positive results observed, the study has opened windows for improvement in terms of adding new activities to Workshop 2 that was capable of acquainting students with knowledge on aerodynamics. This new addition could open better sports products that could promise superior quality and educate the students on concepts such as terminal velocity, which is remarkably addressed in aviation and space technology fields. Moreover, the facilitator was very much looking forward to opening pathways for the student to design a new sports equipment/game applying the scientific concepts that were introduced in the activities of Workshop 2. Although the workshop provided ample opportunities for identifying and learning different materials, their physical properties, and their behavior under the limited school laboratory testing conditions, it promises a future scope for experimenting state of art testing conditions such as scanning electron microscopy (SEM) for better results. Resultantly, tests such as SEM analysis will be able to test the water absorption of concrete walls and concrete composition to microscopic detail. Drazan et al. [39-42] experimented in basketball events, exploring different perspectives of implementing science and engineering curriculum. The studies provide us with a solid background, thereby demonstrating opportunities for students in designing performance monitoring devices by analyzing the player performance. The students can relate to the application of analytics in real-life scenarios through similar additional projects.

Threats were minimally observed while assessing the SIS program; however, the facilitator noticed that the students were exhibiting behavioral setbacks while acknowledging failures. Since the design project was carried out through trial-and-error methods, a few students showed impatience and reluctance in moving forward during lapses in the experiment. Moreover, few students did withdraw from the program, which seemed to affect the morale of their peers, causing further setbacks. Meanwhile, the facilitator ensured that the remaining group members were always motivated with positive remarks and applause to heighten their interest.

\section{Conclusions}

Sports, being one of the critical motivators that contribute toward upbringing socially intimidated youth to the forefront, is also favored by educators around the globe for enhancing their academic and creative development. The implementation of the sportsdriven program, "Science in Sport," in an informal school setting exercising diverse STEM workshops that lead to engineering design challenges, could enhance high school students' inclination toward STEM fields and careers. Participants, self-motivated by sports, bolstered competencies by engaging through the engineering design process while developing a sports product during the challenge. The program exploited the students' enthusiasm in sports to participate in an inquiry-driven learning approach to experience design and engineering. The program outcome also offers opportunities for student enthusiasm and pride through product achievements. They expressed this by learning and applying science concepts such as friction, density, and material compactness in engineering design. The positive observations during the experimental phase complemented the pre-post questionnaires' statistical analysis results that interpreted the improvement in their attitudes toward STEM fields and careers. A normalized analysis of pre-post workshop attitude improvement did highlight the effect of the study on rural- and urban-based participants. The SWOT matrix laid out the strengths of the well-structured program, in addition to the limitations in providing an analysis of participant performance in international standard assessment tests as the aftermath.

The program keenly considers room for expansion with new activities and engineering challenges that could pave for an exciting STEM career pathway. This study can be replicated with university undergraduate students (UG) from sports science disciplines as a capacity-building means and enhancing their knowledge base in sports. We expect that the experiment on UG students may influence their career choices and align them toward the scientific background of the sports industry. The study offers scope in constructing 
activities based on aerodynamics, thereby leading students to acquire innovative scientific perspectives and build new sports products. Currently, based on the results of this study, we are experimenting on students' ability to innovate sports games, if successful could be patented in the future. The ultimate goal in future development will align toward heightening the students' competencies and knowledge, preparing them for International research and science exposure.

Supplementary Materials: The following are available online at https:/ / www.mdpi.com/2071-105 0/13/6/3483/s1, Table S1: Questionnaire sample, Table S2: Example of evaluation rubric handed to judges, Tables S3 to S12: Paired-samples statistics (pre/post tests), Figure S1: Different stages of making a concrete bowling ball from making a mould to testing the end products, Figure S2: Students during a concrete boat product challenge, Figure S3: A golf course is set up and tested by the students in the class.

Author Contributions: Conceptualization, R.A. and N.J.A.-T.; methodology, R.A. and N.J.A.-T.; formal analysis, N.S., J.B. and Z.A.; investigation, N.S. and J.B.; resources, R.A. and N.S.; writingoriginal draft preparation, N.S.; writing-review and editing, J.B. and Z.A.; supervision, N.J.A.-T.; project administration, N.J.A.-T. All authors have read and agreed to the published version of the manuscript.

Funding: This research received no external funding.

Institutional Review Board Statement: Not Applicable.

Informed Consent Statement: Informed consent was obtained from all subjects involved in the study.

Data Availability Statement: The data presented in this study are available on request from the corresponding author. The data are not publicly available due to privacy.

Acknowledgments: The authors acknowledge the support from Qatar University Al-Bairaq program to conduct the study.

Conflicts of Interest: The authors declare no conflict of interest.

\section{References}

1. Brannagan, P.M.; Giulianotti, R. Qatar, global sport and the 2022 FIFA world cup. In Leveraging Legacies from Sports Mega-Events: Concepts and Cases; Springer: Berlin/Heidelberg, Germany, 2014; pp. 154-165.

2. Jaitman, L.; Scartascini, C. Deporte Para el Desarrollo. Banco Interamericano de Desarrollo. Departamento de Investigación y Economista Jefe. III. Título. IV. Serie. 2017. Available online: https://publications.iadb.org/publications/spanish/document/Deporte-para-eldesarrollo.pdf (accessed on 25 November 2020).

3. Craig, E.; Thomas, R.; Hou, C.; Mathur, S. No Shortage of Talent: How the Global Market is Producing the STEM Skills Needed for Growth. Accenture Institute for High Performance (October, 2011). 2011. Available online: www.accenture.com/institute (accessed on 5 December 2020).

4. Van Aalderen-Smeets, S.I.; Walma van der Molen, J.H.; Xenidou-Dervou, I. Implicit STEM ability beliefs predict secondary school students' STEM self-efficacy beliefs and their intention to opt for a STEM field career. J. Res. Sci. Teach. 2019, 56, 465-485. [CrossRef]

5. Banning, J.; Folkestad, J.E. STEM education related dissertation abstracts: A bounded qualitative meta-study. J. Sci. Educ. Technol. 2012, 21, 730-741. [CrossRef]

6. Sahin, A. STEM clubs and science fair competitions: Effects on post-secondary matriculation. J. Stem Educ. 2013, 14, 5-11.

7. Sahin, A.; Top, N. Teachers' Reflections on STEM Students on the Stage (SOS) Model. In A Practice-Based Model of STEM Teaching; Brill Sense: Rotterdam, The Netherlands, 2015; pp. 205-224.

8. Abdulwahed, M.; Ghani, S.; Hasna, M.O.; Hamouda, A. Life Is Engineering Program: Impact of an Engineering Outreach Project in K-12. In Proceedings of the 2013 IEEE Global Engineering Education Conference (EDUCON), Berlin, Germany, 13-15 March 2013; pp. 827-833.

9. Osman, I.H.; Anouze, A.L.; Irani, Z.; Lee, H.; Medeni, T.D.; Weerakkody, V. A cognitive analytics management framework for the transformation of electronic government services from users' perspective to create sustainable shared values. Eur. J. Oper. Res. 2019, 278, 514-532. [CrossRef]

10. Shediac, R.; Samman, H. Meeting the Employment Challenge in the GCC The Need for a Holistic Strategy. Available online: https:/ / www.iqpc.com/media/8251/10415.pdf (accessed on 1 December 2020).

11. Weber, A.S. Linking Education to Creating a Knowledge Society: Qatar's Investment in the Education Sector. In Handbook of Research on Higher Education in the MENA Region: Policy and Practice; IGI Global: Hershey, PA, USA, 2014; pp. 52-73. 
12. Sadler, P.M.; Sonnert, G.; Hazari, Z.; Tai, R. Stability and volatility of STEM career interest in high school: A gender study. Sci. Educ. 2012, 96, 411-427. [CrossRef]

13. Wendell, K.; Connolly, K.; Wright, C.; Jarvin, L.; Rogers, C.; Barnett, M.; Marulcu, I. Incorporating Engineering Design into Elementary School Science Curricula. In Proceedings of the American Society for Engineering Education Annual Conference \& Exposition, Louisville, Kentucky, 20-23 June 2010.

14. Aschbacher, P.R.; Ing, M.; Tsai, S.M. Boosting student interest in science. Phi Delta Kappan 2013, 95, 47-51. [CrossRef]

15. George, P.S. The Middle School-And Beyond; ERIC. 1992. Available online: https:// eric.ed.gov/?id=ED343254 (accessed on 21 March 2021).

16. Kilpatrick, M.; Hebert, E.; Bartholomew, J. College students' motivation for physical activity: Differentiating men's and women's motives for sport participation and exercise. J. Am. Coll. Health 2005, 54, 87-94. [CrossRef]

17. Vallerand, R.J.; Losier, G.F. An integrative analysis of intrinsic and extrinsic motivation in sport. J. Appl. Sport Psychol. 1999, 11, 142-169. [CrossRef]

18. Choi, J.-S.; Song, J. Students' preferences for different contexts for learning science. Res. Sci. Educ. 1996, 26, 341-352. [CrossRef]

19. Assessment, P.f.I.S.; Co-Operation, O.f.E. Problem Solving For Tomorrow's World: First Measures Of Cross-curricular Competencies From Pisa 2003; OECD Publishing: Paris, France, 2004.

20. Hanrahan, M. The effect of learning environment factors on students' motivation and learning. Int. J. Sci. Educ. 1998, 20, 737-753. [CrossRef]

21. OECD. Understanding the Brain: Towards a New Learning Science; OECD Paris: Paris, France, 2002.

22. Dewey, J. Experience and Education. Educ. Forum 1997, 50, 241-252. [CrossRef]

23. Strong, W.B.; Malina, R.M.; Blimkie, C.J.; Daniels, S.R.; Dishman, R.K.; Gutin, B.; Hergenroeder, A.C.; Must, A.; Nixon, P.A.; Pivarnik, J.M. Evidence based physical activity for school-age youth. J. Pediatrics 2005, 146, 732-737. [CrossRef] [PubMed]

24. Pellegrini, B.J. Materials World Modules-2002: A Nationally Representative Evaluation of Classroom Gains. J. Mater. Educ. 2010, $32,185$.

25. Minner, D.D.; Levy, A.J.; Century, J. Inquiry-based science instruction-what is it and does it matter? Results from a research synthesis years 1984 to 2002. J. Res. Sci. Teach. Off. J. Natl. Assoc. Res. Sci. Teach. 2010, 47, 474-496.

26. Contributors, W. FRC Bowling Ball Competition. Available online: https://www.concrete.org/students/studentcompetitions/ frcbowlingballcompetition.aspx (accessed on 13 December 2020).

27. Sirianni, V.L.; Lee, K.L.; LeFevre, M.D.; Lindholm, J.W.; Aghayere, A.; Valentine, M. Assessing the Impact of the Concrete Canoe and Steel Bridge Competitions on Civil Engineering Technology Students. In Proceedings of the 2003 American Society for Engineering Education Annual Conference \& Exposition, Salt Lake City, UT, USA, 20-23 June 2003.

28. Kitchen, J.A.; Sonnert, G.; Sadler, P.M. The impact of college-and university-run high school summer programs on students' end of high school STEM career aspirations. Sci. Educ. 2018, 102, 529-547. [CrossRef]

29. Mohr-Schroeder, M.J.; Jackson, C.; Miller, M.; Walcott, B.; Little, D.L.; Speler, L.; Schooler, W.; Schroeder, D.C. Developing Middle School Students' Interests in STEM via Summer Learning Experiences: See Blue STEM Camp. Sch. Sci. Math. 2014, 114, $291-301$. [CrossRef]

30. Anjarsari, P.; Prasetyo, Z.; Susanti, K. Developing Technology and Engineering Literacy for Junior High School Students through STEM-Based Science Learning. J. Phys. Conf. Ser. 2020, 1440, 012107. [CrossRef]

31. Halim, L.; Soh, T.; Arsad, N. The effectiveness of STEM mentoring program in promoting interest towards STEM. Proc. J. Phys. Conf. Ser. 2018; 1088, p. 012001.

32. Schwichow, M.; Zimmerman, C.; Croker, S.; Härtig, H. What students learn from hands-on activities. J. Res. Sci. Teach. 2016, 53, 980-1002. [CrossRef]

33. Turner, K. Materials world modules: A view from the science classroom. J. Mater. Educ. 2010, 32, 241.

34. Conrad, R.-M.; Donaldson, J.A. Engaging the Online Learner: Activities and Resources for Creative Instruction; John Wiley \& Sons: Hoboken, NJ, USA, 2011.

35. Teppo, M.; Soobard, R.; Rannikmäe, M. A Study Comparing Intrinsic Motivation and Opinions on Learning Science (Grades 6) and Taking the International PISA Test (Grade 9). Educ. Sci. 2021, 11, 14. [CrossRef]

36. Martin, S.H. Environment-Behaviour Studies in the Classroom. J. Des. Technol. Educ. 2009, 9, 77-89.

37. Yager, R.E.; Penick, J.E. Perceptions of four age groups toward science classes, teachers, and the value of science. Sci. Educ. 1986, 70, 355-363. [CrossRef]

38. Jones, S.; Myhill, D. 'Troublesome boys' and 'compliant girls': Gender identity and perceptions of achievement and underachievement. Br. J. Sociol. Educ. 2004, 25, 547-561. [CrossRef]

39. Drazan, J.F.; Scott, J.M.; Hoke, J.I.; Ledet, E.H. Using Biomedical Engineering and "Hidden Capital" to Provide Educational Outreach to Disadvantaged Populations. In Proceedings of the 2014 36th Annual International Conference of the IEEE Engineering in Medicine and Biology Society, Chicago, IL, USA, 26-30 August 2014; pp. 5160-5163.

40. Drazan, J.F.; Danielsen, H.; Vercelletto, M.; Loya, A.; Davis, J.; Eglash, R. A Case Study for Integrated STEM Outreach in an Urban Setting Using a Do-It-Yourself Vertical Jump Measurement Platform. In Proceedings of the 2016 38th Annual International Conference of the IEEE Engineering in Medicine and Biology Society (EMBC), Orlando, FL, USA, 16-20 August 2016; pp. 3027-3030. 
41. Drazan, J.F.; Loya, A.K.; Horne, B.D.; Eglash, R. From Sports to Science: Using Basketball Analytics to Broaden the Appeal of Math and Science among Youth. In Proceedings of the MIT-Sloan Sports Analytics Conference, Boston, MA, USA, 3-4 March 2017; pp. 1-16.

42. Drazan, J.F. Biomechanists can revolutionize the STEM pipeline by engaging youth athletes in sports-science based STEM outreach. J. Biomech. 2020, 99, 109511. [CrossRef] [PubMed] 